\title{
Distribution of Chinese pangolin (Manis pentadactyla) in Nagarjun forest of Shivapuri Nagarjun National Park, Nepal
}

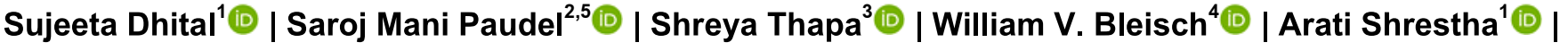 \\ Narayan Prasad Koju ${ }^{1,2,6 * \text { (iD }}$ \\ ${ }^{1}$ Central Department of Environmental Science, Institute of Science and Technology, Tribhuvan University, Kathmandu, Nepal \\ ${ }^{2}$ Center for Postgraduate Studies, Nepal Engineering College, Lalitpur \\ ${ }^{3}$ Nayaa Aayam Multidisciplinary Institute (NAMI College), Kathmandu, Nepal \\ ${ }^{4}$ China Exploration and Research Society, Hong Kong \\ ${ }^{5}$ Shivapuri Nagarjun National Park, Department of National Parks and Wildlife Conservation, Kathmandu, Nepal \\ ${ }^{6}$ Department of Psychology, University of Washington, Seattle, USA \\ * Correspondence: npkoju.2003@gmail.com
}

Received: 18 October 2019 | Revised: 27 June 2020 | Accepted: 29 June 2020

\begin{abstract}
The Chinese pangolin (Manis pentadactyla) is one of the world's critically endangered species, and its distribution is little known in Nepal. This study aimed at understanding the distribution of Chinese pangolin in Nagarjun forest of Shivapuri-Nagarjun National Park, Nepal from September 2017 to May 2018. A total of 15 infrared cameras were used, these were installed randomly in the forest. Only three cameras at three different locations were able to capture photographs of Chinese pangolin. Altogether, three events, comprising 21 still photos of pangolin, their sign and other mammal species in the area were recorded. In addition, 94 pangolin burrows were noticed in the study area. The distribution of Chinese pangolin is influenced by the food, tree canopy and aspect of the area. Majority of the active burrows were found near to feeding burrows where ants and termite's nest were found abundantly. In addition to Chinese pangolin, the study was able to capture twelve mammalian species including masked palm civet (Paguma larvata) and yellowthroated marten (Martes flavigula). These two species were often seen to enter or try to enter the active burrows of pangolins. The results suggest that Nagarjun Forest serves an important role in mammal conservation with high mammalian biodiversity.
\end{abstract}

Keywords: Burrows, Camera traps, Critically endangered, Mammals

\section{1 | Introduction}

Pangolins (Manis spp.) are Evolutionarily Distinct and Globally Endangered (EDGE) mammals constituting the order Pholidota (Gaubert \& Antunes 2005). Often called "scaly anteater", pangolins possess scale-covered bodies and feed on ants and termites (Thomas and Lydekker 1911). They are nocturnal, shy, non- aggressive, solitary and elusive burrowing mammals (Wilson 1994) which have received little scientific attention till date (Pantel \& Chin 2009, Challender \& Waterman 2017). Pangolins roll into a ball as a defense such that all soft tissues are hidden or protected by scales (Heath \& Vanderlip 1988). They play an important role in controlling ant and termite populations in natural ecosystems (Wu et al. 2004). Eight extant species of pangolins are recognized (Gaudin et al. 2009), with four species distributed in the Afro-tropics and four species in the Indo-Malayan regions of Asia. All species are listed as threatened on the International Union for Conservation of Nature Red List (IUCN 2019). Currently, all the species are under Appendix I of the Convention on International Trade in Endangered Species of Wild Fauna and Flora (CITES 2019).

Nepal supports the occurrence of two pangolins species, Chinese pangolin (Manis pentadactyla) and Indian pangolin (M. crassicaudata) (Gurung et al. 1996, Baral \& Shah 2008, Jnawali et al. 2011, Suwal 2011, Bhandari \& Chalise 2014, Thapa et al. 2014, Sharma 2017, Katuwal et al. 2017, DNPWC \& DoF 2018, Khatiwada 2020, Sharma et al. 2020a, b, c, d, Suwal et al. 2020). Globally, the species is reported up to $3000 \mathrm{~m}$ of elevation (Challender et al. 2019), however in Nepal the species is found up to 2406 m of elevation (Thapa et al. 2014). Chinese pangolin is reported from 25 districts of Nepal (DNPWC \& DoF 2018). Chinese pangolins are found in a wide range of habitats, including 
primary and secondary tropical forests, limestone forests, bamboo forests, broad-leaf and coniferous forests, grasslands and agricultural fields in both protected and non-protected areas (Gurung 1996, Chao 2001, Katuwal et al. 2017, Sharma et al. 2020a, Suwal et al. 2020). Their occurrences in these wider habitats are influenced by different covariates, such as forest, canopy cover, soil type, aspect, ground vegetation, water, and anthropogenic factors such as poaching, human settlements and agricultural land (Gurung et al. 1996, Baral \& Shah 2008, Jnawali et al. 2011, Suwal 2011, Bhandari \& Chalise 2014, Sharma 2017, Khatiwada 2020, Sharma et al. 2020a, b, c, d, Suwal et al. 2020). This species generally digs their own burrows and sometimes enlarge passages made by termites (Heath \& Vanderlip 1988). They used these burrows for termites foraging and to sleep (Newton 2008). The home range size of the species is assumed less than $1 \mathrm{~km}^{2}$ (Heath \& Vanderlip 1988) although the concrete data is lacking. Chinese pangolin's ecology and their behavior is little known in Nepal (Gurung 1996, Bhandari \& Chalise 2014), however people's knowledge on the species role in an ecosystem indicated some of the information on their ecological role (Sharma et al. 2020c). Due to illegal trade and habitat destruction (Katuwal et al. 2017, Sharma 2017, Ghimire et al. 2020, Sharma et al. 2020d), the population of the Chinese pangolin is decreasing at an alarming rate (Challender et al. 2019). Even though Chinese pangolin is critically endangered species, its current spatial distribution in some of the areas of Nepal is little known. It may create problem to develop site- and species-specific management plan. Therefore, we aimed to explore the distribution of Chinese pangolin in Nagarjun forest near by Kathmandu city using infrared cameras.

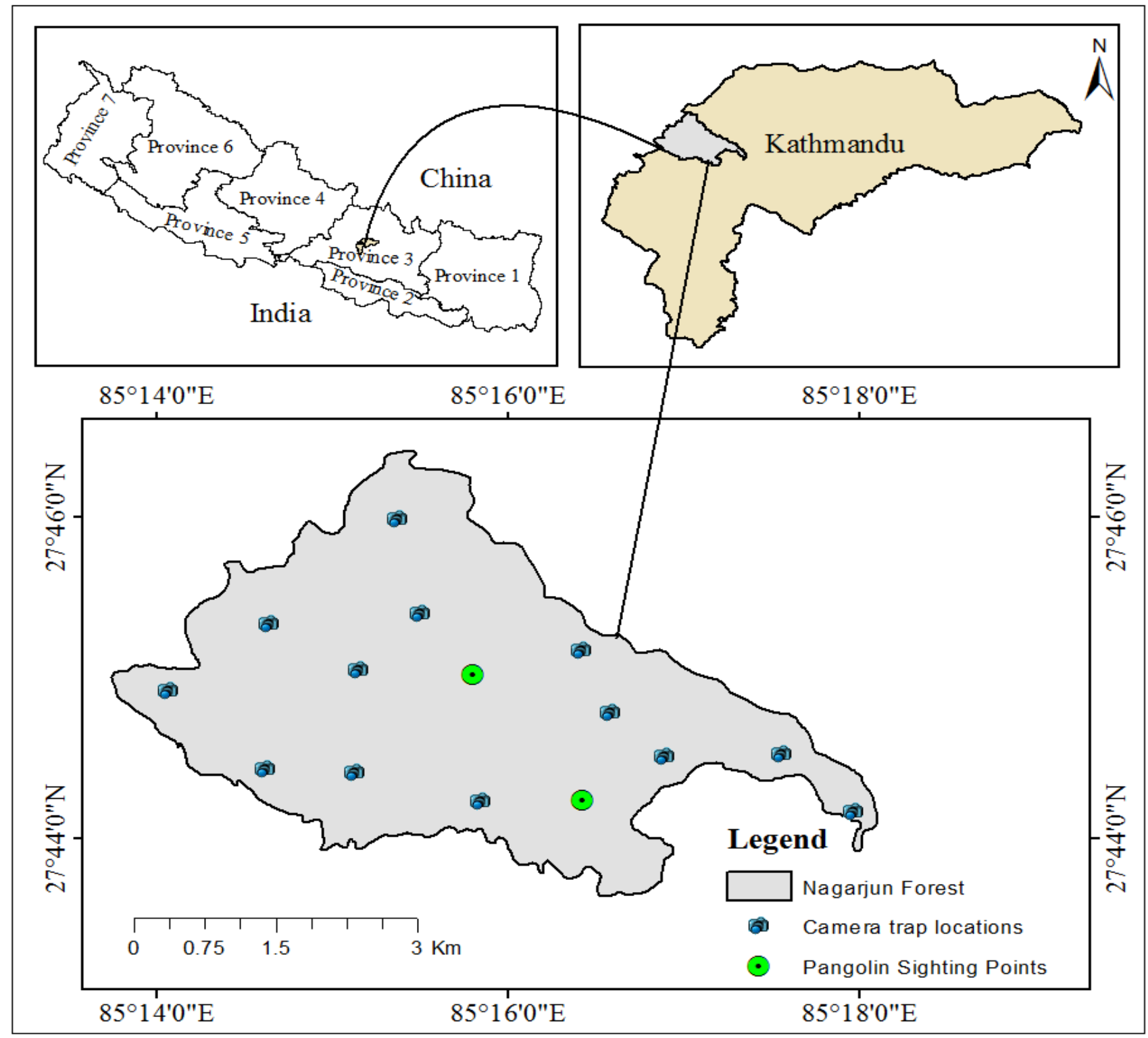

Figure 1. Map of the Nagariun forest of SNNP showing camera trap locations 


\section{2 | Materials and methods}

\section{1 | Study area}

The study was focused in Nagarjun forest, a part of the ShivapuriNagarjun National Park (SNNP) $\left(27^{\circ} 43^{\prime} 37.13^{\prime \prime}\right.$ to $27^{\circ} 46^{\prime} 22.84^{\prime \prime} \mathrm{N}$ and $85^{\circ} 13^{\prime} 2.97^{\prime \prime}$ to $85^{\circ} 18^{\prime} 14.38^{\prime \prime}$ E). Nagarjun forest covers an area of about $15 \mathrm{~km}^{2}$ of Shivapuri-Nagarjun National Park (DNPWC 2019) between the elevation of $1350 \mathrm{~m}$ to $2100 \mathrm{~m}$ asl

(Fig. 1). Nagarjun forest supports a mid-hill forest ecosystem and has a sub- tropical climate grading to temperate climate (SNNP 2017).

\section{2 | Data collection}

A preliminary study was carried out from 5-6 August 2017 to conceptualize the conditions of the forest before starting research. During survey, potential sites of pangolin were identified while walking around the forest with National Park staff. Different types of burrows belonging to pangolin were recorded throughout the study site along elevational gradients by opportunistic sampling method between November and December 2017. Number of active burrows, feeding burrows and passive burrows were counted. The burrows that were less deep visually with small opening hole were classified as feeding burrows (Mahmood et al. 2013). Likewise, the burrows that had leaves, spider webs, dry and compact soils were considered to be passive burrow and the burrow that had fresh, loose soil and fresh scratched marks were taken as active burrows (Suwal 2011, Katuwal et al. 2017, Sharma 2017, Sharma et al. 2020b). A square plot of $10 \mathrm{~m} \times 10$ $\mathrm{m}$ was established keeping burrow at the centre of the plot for collecting information on habitat covariates. The habitat covariates including elevation, aspect, canopy cover (\%) and presence/absence of food source (number of ant nests/termite mounds) were also noted to determine the habitat preference of the species. The latitude and longitude, elevation and aspect of burrows were recorded by using GPS Garmin Etrex 30 and android app clinometer-bubble, respectively. Visual estimation was done for the canopy cover and ground cover keeping burrows at centre of the plot. A total of 15 infrared cameras were set in site with reference to fresh/active burrows used by pangolins following the method of Marler (2016). Cameras were set near active pangolin burrow around 1-2 feet above the ground depending on the slope of the land and were set at least $500 \mathrm{~m}$ apart from each (Fig. 1). Camera trapping was carried out from September 2017 to May 2018 at elevations between 1350 m asl and $2100 \mathrm{~m}$ asl. Two types of Bushnell Trophy Camera were used: Model \#119537C and Model \#119405C. These cameras were set with one-second trigger time between trigger events to take photographs of Chinese pangolin. The cameras functioned for 24-hours each day, and used infrared Light Emitting Diode to capture night images. Data and images collected by the cameras were downloaded at interval of 15 days, and the status of camera, battery and memory card were also checked.

\section{3 | Results}

A total of 94 burrows were recorded in Nagarjun forest of Shivapuri-Nagarjun National Park, of which 10 were active burrows, 62 passive burrows and 22 feeding burrows. The feeding burrows were recorded near to living burrows with ants' nests and termite molds. Most burrows (41.48\%) were distributed in East aspect and few (6.38\%) were found in South East aspect. Most of the burrows $(69.14 \%)$ were distributed in dense forested area having canopy cover between $25 \%-50 \%$. Majority of the burrows $(79.78 \%)$ were distributed between the elevational ranges of $1400-1600 \mathrm{~m}$ asl. Burrows were not observed at elevations between 1600-1700 m asl and 1800-1900 m asl, and few burrows were found between $1700-1800 \mathrm{~m}$ asl (4.2\%) and $2000-2100 \mathrm{~m}$ asl $(15.93 \%)$. A total of three events consisting of 21 photographs were recorded throughout the study period. Even though cameras were set in September 2017, the first photograph of pangolin capture was recorded on 27 December 2017 at 20:06 at elevation of $1400 \mathrm{~m}$ asl (Supplementary Fig. 1, Photograph 1). A second event of pangolin was captured on December 31, 2017 at 01:55 at elevation of $1900 \mathrm{~m}$ asl (Supplementary Fig. 1, Photograph 2). In this event, three images of a pangolin crossing the trail were captured. During January, a rapid growth in numbers of fresh feeding burrows around the site of installed cameras was observed over the course of two week (Supplementary Fig. 1, Photograph 3). Following the appearance of new fresh burrows, the final event of the pangolin's camera capture of this study was recorded on 27 February 2018. On that day, 12 photos were recorded. During the study period (September 2017 to May 2018), twelve mammalian species other than Chinese pangolin were recorded by camera traps. The recorded mammalian species were Assamese macaque (Macaca assamensis), barking deer (Muntiacus vaginalis), crested porcupine (Hystrix indica), masked palm civet (Paguma larvata), Leopard cat (Prionailurus bengalensis), sambar deer (Rusa 
unicolor), leopard (Panthera pardus), orange-bellied Himalayan squirrel (Dremomys lokriah), yellow-throated marten (Martes flavigula), jungle cat (Felis chaus), large Indian civet (Vivera zibetha) and wild boar (Sus sp.) (Supplementary Fig. 1, Photograph 4-15).

\section{4 | Discussion}

The burrows of Chinese pangolin in Nagarjun forest of ShivapuriNagarjun National Park are randomly distributed along elevational gradients. Termite abundance and its colony size might be the possible factors to determine the number of pangolins, as observed in Manis temminckii by Swart et al. (1999). The distribution of ants and termites were also found to be random with respect to aspect in the study areas and so were the burrows. The preference of Chinese pangolin for burrow construction towards east and south aspects (Gurung 1996, Acharya 2001, Wu et al. 2003, Wu et al. 2004) might be for providing direct light penetration to the burrows potentially for maintaining the temperature during the winter season. However, more study is needed for year-round including summer season to confirm their preferences. In addition, the occurrence of Chinese pangolin in this area might also be influenced from the people's movement for pilgrim visit. Generally, their detection probability is low in human dominated landscape (non-protected area) than low human influenced area (protected area) (Sharma et al. 2020b).

The occurrence of Chinese pangolin was found under the moderate dense canopy cover $(25 \%$ - 50\%) probably for getting more termites and ants, and easier to construct burrows due to less litter fall on the ground. Our finding corroborates with other findings of Bhandari and Chalise (2014), Dorji et al. (2016), Katuwal et al. (2017) and Sharma et al. (2020b). The higher density of termites and other prey species occur in drier areas under the canopy cover $<50 \%$, and potentially it prevents the excessive soil erosion (Hemachandra et al. 2014, Katuwal et al. 2017).

The higher abundance of burrows between the elevational range of $1400 \mathrm{~m}$ asl $-1600 \mathrm{~m}$ asl indicated the most preferred habitat of Chinese pangolin in the study area, however, our study has limited cameras to capture the evidences. At higher elevation, i.e. between $1800 \mathrm{~m}$ asl $-2000 \mathrm{~m}$ asl, the least number of burrows are recorded, which might be because of less suitable habitat having sloppy or stiff areas or the continuous flow of people to reach Jamacho Tower (a pilgrimage spot).
Chinese pangolin co-occurs with several other mammalian species in study area. Captured photographs and videos revealed that there might be some association between the pangolin and Masked palm civet and Yellow-throated marten, which were seen entering or try to enter the burrows of pangolins. It is possible that there is some prey-predator relationship existing between these three mammals, or these species may depend on pangolins burrows for foraging or dinning. Thus, further study of the pangolin may also contribute to the conservation of other mammalian species in the study area.

\section{5 | Conclusions}

Chinese pangolins were distributed randomly in Nagarjun forest of Shivapuri Nagarjun National Park and are hard to capture in infrared camera. Their distribution is influenced by various factors like elevation, aspect, trees' canopy cover and food availability. Feeding burrows were near active burrows in regions where ants and termites were distributed in higher numbers and were away from external disturbances.

\section{6 | Research Implications}

This research work has confirmed the presence of critically endangered Chinese pangolin from Nagarjun forest through photographical evidence. Hence, this work can help in the conservation of this species significantly in that area.

\section{Acknowledgements}

We would like to thank Department of National Parks and Wildlife Conservation and Ministry of Forest, Nepal for giving permission to conduct research. We would also like to thank the staff of Shivapuri-Nagarjun National Park. The study was supported by Kathmandu Center for Research and Education (KCRE), CASTU, the China Exploration and Research Society, and the Ministry of Education, Science and Technology, Nepal. We are thankful to both reviewers for their valuable and constructive comments to shape the manuscript.

\section{Authors' contributions}

Dhital, S. designed the research, and collected data; Paudel, S. M. worked for camera trapping; Thapa, S. collected data, and wrote the manuscript; Bleisch, W. V. helped in field work and wrote manuscript; Shrestha, A. analyzed the data and wrote the 
manuscript; Koju, N. P. supervised research work and wrote the manuscript.

\section{Conflicts of interest}

Authors declare no conflict of interest.

\section{ORCID}

Sujeeta Dhital (ID https://orcid.org/0000-0003-2302-4657

Sarojmani Pouel (D) https://orcid.org/0000-0001-9668-0300

Shreya Thapa (D) https://orcid.org/0000-0001-5317-2998

William V. Bleisch (iD https://orcid.org/0000-0001-6549-5823

Arati Shrestha (iD https://orcid.org/0000-0001-5180-8526

Narayan Prasad Koju (D) https://orcid.org/0000-0002-4303-0520

\section{References}

Acharya, P. M. 2001. Status and distribution of pangolin in the Nagarjun forest in Central Nepal. Workshop on Asian Pangolin, 17-18 December 2001, Taipei, Taiwan.

Baral, H. S. and Shah, K. B. 2008. Wild mammals of Nepal. Himalayan Nature. Kathmandu, Nepal, p 94.

Bhandari, N. and Chalise, M. K. 2014. Habitat and distribution of Chinese pangolin (Manis pentadactyla Linnaeus, 1758) in Nagarjun forest of Shivapuri Nagarjun National Park. Nepalese Journal of Zoology 2(1):18-25.

Challender, D. and Waterman, C. 2017. Implementation of CITES decisions 17.239 b) and 17.240 on pangolins (Manis spp.), p 124.

Challender, D., Wu, S., Kaspal, P., Khatiwada, A., Ghose, A., Sun, N. C. -M. et al. 2019. Manis pentadactyla (errata version published in 2020 T12764A168392151). The IUCN Red List of Threatened Species 2019 e. https://dx.doi.org/10.2305/ IUCN.UK.2019- 3. RLTST 12764A168392151 en. Accessed on 06 July 2020.

Chao, J. T. 2001. General status of Formosan pangolin Manis pentadactyla pentadactyla (Abs). Workshop on Asian Pangolin, 17-18 December 2001, Taipei, Taiwan,

CITES. 2019. Appendices I, II and III. https://cites.org/eng/app/appendices.php. Accessed on 23 June 2020.

DNPWC and DoF. 2018. Pangolin Conservation Action Plan for Nepal (2018-2022). Department of National Parks and Wildlife Conservation and Department of Forests, Kathmandu, Nepal.

DNPWC. 2019. Shivapuri Nagarjun National Park https://dnpwc.gov.np/media/publication /Shivapuri brouchure.pdf. Accessed on 11 April 2020.

Dorji, D. 2016. Distribution, habitat use, threats and conservation of the critically endangered Chinese pangolin (Manis pentadactyla) in Samtse District, Bhutan. https://www.rufford.org/files/20287-
1\%20Detailed\%20Final\%20-Report.pdf. Accessed on 10 December 2019

Gaubert, P. and Antunes, A. 2005. Assessing the taxonomic status of the Palawan pangolin Manis culionensis (Pholidata) using discrete morphological characters. Journal of Mammalogy 86:1068-1074. https://doi.org/10.1644/1545-1542(2005)86[1068:attsot]2.0

Gaudin, J. T. and Emry, R. J. 2009. The phylogeny of living and extinct pangolins (Mammalia, Pholidota) and associated taxa: A morphology based analysis. Journal of Mammalian Evolution 16(4):35-304. https://doi.org/10.1007/s10914-009-9119-9

Ghimire, P., Raut, N., Khanal, P., Acharya, S. and Upadhaya, S. 2020. Species in peril: assessing the status of the trade in pangolins in Nepal. Journal of Threatened Taxa 12(8):15776-15783.

Gurung, J. B. 1996. Pangolin survey in Royal Nagarjung Forest in Kathmandu, Nepal. Tigerpaper 23(2):29-32.

Heath, M. E. and Vanderlip, S. L. 1988. Biology, husbandry, and veterinary care of captive Chinese pangolins (Manis pentadactyla). Zoo Biology 5(4):387-390.

Hemachandra, I. I., Edirisinghe, J. P., Karunaratne, I., Gunatilleke, C. V. S. and Fernando, R. S. 2014. Diversity and distribution of termite assemblages in montane forests in the Knuckles Region, Sri Lanka. International Journal of Tropical Insect Science 34:41-52. https://doi.org/10.1017/S174275841300043X

https://dnpwc.gov.np/media/publication/Shivapuri brouchure.pdf. Accessed on 11 April 2020.

IUCN. 2019. The IUCN Red List of Threatened Species. https://www.iucnredlist.org/. Accessed on 26 June 2020.

Jnawali, S. R., Baral, H. S., Lee, S., Acharya, K. P., Upadhyay, G. P., Pandey, M. et al. 2011. The Status of Nepal Mammals: The National Red List Series, Department of National Parks and Wildlife Conservation, Kathmandu, Nepal.

Katuwal, H. B., Sharma, H. P. and Parajuli, K. 2017. Anthropogenic impacts on the occurrence of the critically endangered Chinese pangolin (Manis pentadactyla) in Nepal. Journal of Mammalogy 98(6):1667-1673. https://doi.org/10.1093/jmammal/gyx114

Khatiwada, A. P., Suwal, T. L., Wright, W., Roe, D., Kaspal, P., Thapa, S. et al. 2020. Community conservation in Nepal opportunities and challenges for pangolin conservation. In: Challender, D.W.S., Nash, H.C. and Waterman, H.C. (Eds.) Pangolins Science, Society and Conservation, Academic Press, pp 395409.

Mahmood, T., Jaben, K., Hussain, I. and Kayani, A. R. 2013. Plant species association, burrow characteristics and the diet of the Indian pangolin, Manis crassicaudata, in the Potohar Plateau. Pakistan Journal of Zoology 45(6):1533-1539. 
Marler, P. N. 2016. Camera trapping the Palawan Pangolin Manis culionensis (Mammalia: Pholidota: Manidae) in the wild. Journa of Threatened Taxa 8(12):9443-9448.

Newton, P., Nguyen V. T., Robertson, S. and Bell, D. 2008. Pangolins in peril: using hunter's knowledge to conserve elusive species in Vietnam. Endangered Species Research 6:41-53.

Pantel, S. and Chin, S. Y (eds.). 2009. Proceedings of the workshop on trade and conservation of pangolins native to south and southeast Asia, 30 June - 2 July 2008, Singapore Zoo Singapore. TRAFFIC Southeast Asia, Petaling Jaya, Selangor, Malaysia.

Sharma, S. 2017. Impacts of the Gorkha earthquake 2015 on the Chinese pangolin (Manis pentadactyla Linnaeus, 1758) in Chautara Municipality of Sindhupalchowk, Nepal. M.Sc. Thesis. Tribhuvan University, Kirtipur, Kathmandu, Nepal.

Sharma, H. P., Rimal, B., Zhang, M., Sharma, S., Poudyal, L. P., Maharjan, S. et al. 2020a. Potential distribution of the critically endangered Chinese Pangolin (Manis pentadactyla) in different land covers of Nepal: Implications for conservation. Sustainability 12(3):1282. https://doi.org/10.3390/su12031282

Sharma, S., Sharma, H. P., Chaulagain, C., Katuwal, H. B. and Belant, J. L. 2020b. Estimating occupancy of Chinese pangolin (Manis pentadactyla) in a protected and non-protected area of Nepal. Ecology and Evolution 10(10):4303-4313. https://doi.org/10. 1002/ece3.6198

Sharma, S., Sharma, H. P., Katuwal, H. B. and Belant, J. L. 2020c Knowledge of the Critically Endangered Chinese pangolin (Manis pentadactyla) by local people in Sindhupalchok, Nepal. Global Ecology and Conservation 23:e01052. https://doi.org/10.1016/j.gecco.2020.e01052

Sharma, S., Sharma, H. P., Katuwal, H. B., Chaulagain, C. and Belant, J. L. 2020d. People's knowledge of illegal Chinese pangolin trade routes in central Nepal. Sustainability 12(12):4900.

SNNP. 2017. Shivapuri Nagarjun National Park and Buffer Zone draft management plan fiscal year 074/075-078/079 (2017-2021). A booklet published by Department of National Parks and Wildlife Conservation Kathmandu, Nepal. Government of Nepal.

Suwal, T. L. 2011. Status, distribution, behavior and conservation of Pangolins in private and community forests of Balthali in Kavre, Nepal. MSc Thesis, Tribhuvan University, Kirtipur, Kathmandu, Nepal.

Suwal, T. L., Thapa, A., Gurung, S., Aryal, P. C., Basnet, H., Basnet, K. et al. 2020. Predicting the potential distribution and habitat variables associated with pangolins in Nepal. Global Ecology and Conservation 23:e01049. https://doi.org/10.1016/j.gecco.2020.e01049
Swart, J. M., Richardson, P. R. K. and Ferguson, J. W. H. 1999. Ecological factors affecting the feeding behaviour of pangolins (Manis temminckii). Journal of Zoology 247:281-292.

Thapa, P., Khatiwada, A. P., Nepali, S. C. and Paudel, S. 2014. Distribution and conservation status of Chinese pangolin (Manis pentadactyla) in Nangkholyang VDC, Taplejung, eastern Nepal. American Journal of Zoological Research 2(1):16-21.

Thomas, O. and Lydekker, R. 1911. 1911 Encyclopaedia Britannica/Pangolin.

https://en.wikisource.org/wiki/1911_Encyclop\%C3\%A6dia_Britan nica/Pangolin. Accessed on 11 April 2020.

Wilson, A. E. 1994. Husbandry of pangolins Manis spp. International Zoo Yearbook 33(1):248-251. https://doi.org/10.1111/j.17481090.1994.tb03578/x.

Wu, S. B., Liu, N. F., Ma, G. Z., Xu, Z. R. and Chen, H. 2003. Habitat selection by Chinese pangolin (Manis pentadactyla) in winter in Dawuling Natural Reserve. Mammalia 67(4):493-502.

Wu, S. B., Liu, N. F., Zhang, Y. and Ma, G. Z. 2004. Assessment of threatened status of Pangolin species (Manis pentadactyla). Chinese Journal of Applied and Environmental Biology 10(4):456-461

\section{Cite this article as:}

Dhital, S., Paudel, S. M., Thapa, S., Bleisch, W. V., Shrestha, A. and Koju, N. P. 2020. Distribution of Chinese pangolin (Manis pentadactyla) in Nagarjun forest of Shivapuri Nagarjun National Park. Nepalese Journal of Zoology 4(1):1-7. https://doi.org/10.3126/njz.v4i1.30667 
Supplementary Figure 1: Photographs 1-15
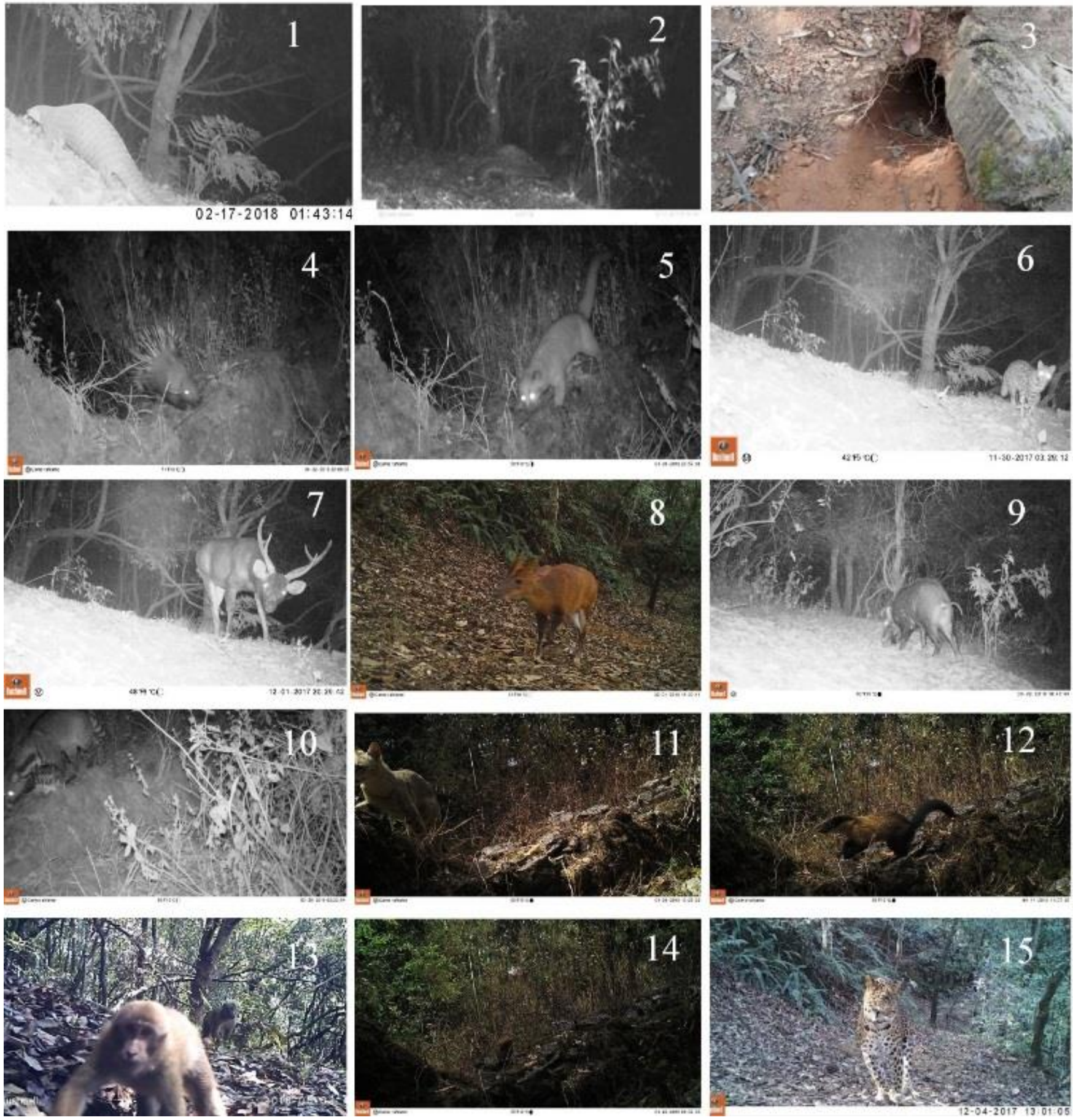

Photograph 1: Chinese pangolin captured by camera trap at elevation of $1400 \mathrm{~m}$ asl; 2: Chinese pangolin captured by camera trap at an elevation of $1900 \mathrm{~m}$ asl; 3: Fresh burrow of Chinese pangolin in Nagarjun forest; 4: Crested porcupine (Hystrix indica); 5: Masked palm civet (Paguma larvata); 6: Leopard cat (Prionailurus bengalensis); 7: Sambar deer (Rusa unicolor); 8: Barking deer (Muntiacus vaginalis); 9: Wild boar (Sus sp); 10: Large indian civet (Vivera zibetha); 11: Jungle cat (Felis chaus); 12: Yellow-throated marten (Martes flavigula); 13: Assamese macaque (Macaca assamensis); 14: Orange- bellied Himalayan squirrel (Dremomys lokriah); 15: Leopard (Panthera pardus). 